\title{
Setting priorities for the health care sector in Zimbabwe using cost-effectiveness analysis and estimates of the burden of disease Kristian Schultz Hansen*1,2 and Glyn Chapman ${ }^{3}$
}

\author{
Address: ${ }^{1}$ Institute of Public Health, Department of Health Services Research, University of Aarhus, Vennelyst Boulevard 6, DK-8000, Aarhus C, \\ Denmark, ${ }^{2}$ DBL-Institute for Health Research and Development, Jaegersborg Alle 1D, DK-2920, Charlottenlund, Denmark and ${ }^{3}$ IMMPACT, \\ University of Aberdeen, 2nd Floor, Foresterhill Lea House, Westburn Road, Aberdeen, AB25 2ZY, UK \\ Email: Kristian Schultz Hansen* - ksh@soci.au.dk; Glyn Chapman - g.chapman@abdn.ac.uk \\ * Corresponding author
}

Published: 28 July 2008

Cost Effectiveness and Resource Allocation 2008, 6:14 doi:10.1/86/1478-7547-6-14

This article is available from: http://www.resource-allocation.com/content/6/1/14

(C) 2008 Hansen and Chapman; licensee BioMed Central Ltd.

This is an Open Access article distributed under the terms of the Creative Commons Attribution License (http://creativecommons.org/licenses/by/2.0), which permits unrestricted use, distribution, and reproduction in any medium, provided the original work is properly cited.
Received: I4 December 2007

Accepted: 28 July 2008

\begin{abstract}
Background: This study aimed at providing information for priority setting in the health care sector of Zimbabwe as well as assessing the efficiency of resource use. A general approach proposed by the World Bank involving the estimation of the burden of disease measured in Disability-Adjusted Life Years (DALYs) and calculation of cost-effectiveness ratios for a large number of health interventions was followed.
\end{abstract}

Methods: Costs per DALY for a total of 65 health interventions were estimated. Costing data were collected through visits to health centres, hospitals and vertical programmes where a combination of step-down and micro-costing was applied. Effectiveness of health interventions was estimated based on published information on the efficacy adjusted for factors such as coverage and compliance.

Results: Very cost-effective interventions were available for the major health problems. Using estimates of the burden of disease, the present paper developed packages of health interventions using the estimated cost-effectiveness ratios. These packages could avert a quarter of the burden of disease at total costs corresponding to one tenth of the public health budget in the financial year 1997/98. In general, the analyses suggested that there was substantial potential for improving the efficiency of resource use in the public health care sector.

Discussion: The proposed World Bank approach applied to Zimbabwe was extremely data demanding and required extensive data collection in the field and substantial human resources. The most important limitation of the study was the scarcity of evidence on effectiveness of health interventions so that a range of important health interventions could not be included in the costeffectiveness analysis. This and other limitations could in principle be overcome if more research resources were available.

Conclusion: The present study showed that it was feasible to conduct cost-effectiveness analyses for a large number of health interventions in a developing country like Zimbabwe using a consistent methodology. 


\section{Background}

There is an increasing number of cost-effectiveness studies aiming at analysing the allocative efficiency of the health care sector. These analyses incorporate costs and effects of interventions directed at different health problems and different patient groups and often include a large number of interventions. Examples from developed countries include analyses performed in United Kingdom [1], Australia [2] and in Oregon State in the USA [3] while a large database on cost-effectiveness analyses from all over the world is maintained by an American university [4]. For developing countries, the World Bank health sector priorities review [5-7] assessed the costs and effectiveness of health interventions directed at major health problems for low and middle income regions of the world. In a similar effort, the World Health Organization estimated costs per DALY for a wide range of health interventions for 14 epidemiologic sub regions and in addition developed tools enabling individual countries to perform similar costeffectiveness analyses based on local estimates on e.g. disease burden and unit costs of various health services [810]. At an individual country level, a list of costs per discounted life year gained for a large number of preventive and curative health interventions was developed for Guinea [11].

While such cost-effectiveness analyses aiming at assessing allocative efficiency may be very useful for setting priorities in the health care sector of a given country, several features of this technique have been identified as being problematic. Since these analyses often include a large number of health interventions, these exercises are extremely data intensive in terms of estimating the required information on costs and effectiveness. Consequently, simplifying assumptions and shortcut methods have been applied in order to make the data collection task more manageable. For instance, it is often assumed that health interventions are produced under constant returns to scale so that the costs per health output do not vary with the scale at which the intervention is undertaken thus making it necessary only to estimate a single point on the cost function $[6,12]$. It is also common practice to exclude important cost categories such as costs borne by patients [13]. Further, required information may be predicted using statistical models rather than actual data collection [9]. A major concern is the severe lack of information on effectiveness of health interventions [14]. Finally, concerns have been raised over the relevance and applicability to priority setting in a particular country of the published allocative cost-effectiveness analyses since these have often been developed as regional estimates [15].

Presently, there is not much knowledge of the relative cost-effectiveness of health services offered in the Zimba- bwean public health care sector. Such information may however be useful for assessing the efficiency of resources used in a situation of dwindling health care funds and steeply increasing demand. The main objective of this paper is therefore to provide input into an analysis of identifying ways of improving the allocative efficiency of resource utilisation in the health care sector of Zimbabwe. The general research strategy for achieving this objective is inspired by the approach previously utilised by the World Bank $[5,6,16,17]$. As a first step, this approach entails the estimation of the level of ill-health of the Zimbabwean population in 1997 using DALYs as the societal health outcome measure. Results of this component have been reported elsewhere [18] and key figures describing the burden of disease by cause in 1997 have been reproduced in Annex 1 of the present paper. The second step involves the estimation of costs per DALY gained for a large number of health interventions followed by the development of essential packages of health interventions which address large amounts of ill-health at low costs. The present paper focuses on the second step. In addition, having finalised this kind of analysis in Zimbabwe, this study also provides an opportunity to discuss the feasibility of conducting this very data intensive World Bank approach in a developing country setting.

\section{The context of the health care system}

At the time of this study, the disease pattern in Zimbabwe is heavily dominated by communicable, maternal, perinatal and nutritional conditions [19] similar to other countries in Sub-Saharan Africa although Zimbabwe is plagued with an unusually large disease burden due to HIV (Annex 1 ). The health of the nation has traditionally been a high priority and large investments in the public health care sector in the 1980s led to impressive improvements in key health indicators although the years following 1990 saw a reversal in most health indicators [20] - a development further exacerbated in more recent time due to decreasing GDP, dwindling health care funds and massive emigration of health sector personnel [21]. The health care sector is a highly heterogeneous section of the economy. Provision of health care services is offered by government, church missions and other NGOs, industries and mines, private practitioners and traditional healers. Measured by the number of health facilities, government is the single most important provider [22]. Private practitioners and hospitals are relatively abundant in larger cities where these providers are able to attract large proportions of the available health personnel. Government of Zimbabwe has succeeded in organising its own institutions as well as church mission facilities and some of the private sector facilities into a four-tiered system of health care service delivery. Health centres manned by qualified nurses are the first level followed at the next levels by district, provincial and central hospitals where hospital services of 
increasing complexity are offered requiring more specialised personnel and equipment. The head office of the Ministry of Health and Child Welfare constitutes the highest level of the public health care sector and it is the main actor in terms of health policy making and development. For instance, the head office is responsible for the allocation of all government health care funds among health facilities as well as steering important processes such as the Zimbabwe Essential Drugs Action Programme (ZEDAP) which results in a list specifying the most costeffective drugs for a large number of health problems [23] that is used extensively by all health facilities in the country.

\section{Methods}

Choice of interventions for the cost-effectiveness analyses Curative interventions for the present study included the treatment of common health problems at hospital inpatient and outpatient departments as well as health centres. These interventions covered both single treatment episodes and more long term management of chronic conditions. Preventive interventions included five vertical activities: residual house spraying to prevent malaria, immunisation of children (measles, polio, tuberculosis, diphtheria, pertussis and tetanus), surveillance and targeted supplementary feeding of wasted children, HIV prevention through improved access to treatment of sexually transmitted infections (STIs) and health promotion of personal and domestic hygiene in order to decrease the incidence of diarrhoeal diseases.

\section{Cost data collection and unit costs estimation at selected study sites}

In order to estimate the costs of individual curative and preventive health interventions, a number of public health providers were visited for the collection of the necessary cost data. Study sites were randomly chosen from all over the country. With respect to curative health interventions, six health centres out of a total of around 1200 were selected for the cost analysis. Health centres offered outpatient services and selected preventive activities such as immunisation. Five district level hospitals including two mission hospitals from a total of 130 hospitals were sampled for the costing of inpatient services, surgical procedures and outpatient services. Finally, two provincial hospitals (from a total of 8 ) were randomly selected and these offered similar services as district hospitals but the former hospitals were able also to provide more specialised services. The highest level, central hospitals, was excluded from the costing analysis. Preventive interventions were organised in a vertical fashion involving provincial health offices and district hospitals as well as services performed by health facilities (e.g. vaccinations at health centres and hospitals). Two provinces out of a total of eight were randomly chosen and two districts were ran- domly selected within each province (a total of 14 districts). Finally, the Ministry of Health Headquarters and two provincial health offices were visited to capture additional programme costs of curative and preventive interventions such as central purchasing of drugs and high level administrative personnel [10].

The costing perspective taken for this study was the health provider's view (Ministry of Health and Child Welfare) since the objective of the present cost-effectiveness analysis was to determine how the largest slice of the burden of disease could be cut using a given government budget [24].

Activities at each study site incorporated the identification, measurement and subsequent valuation of resources required to offer health services. Government accounting systems provided at each study site the level of actual, recurrent expenditure by category including for example salaries by type of personnel, stationery, electricity, maintenance and drugs. With respect to capital inputs at each study site, a quantity surveyor estimated the present day construction costs per square metre by type of office or department. Further, a list of available equipment and furniture was developed and subsequently valued using market prices. From these replacement costs of buildings, equipment and furniture, an annual equivalent was calculated using the annuitization method [24,25] assuming a real discount rate of $3 \%$ and expected life spans of 30,7 and 10 years for the mentioned capital inputs.

These costs by category were at each study site allocated to the health interventions selected for this study. This was done by applying the standard step-down costing methodology $[24,26]$ consisting initially of categorising activities (in practice wards and departments) in a study site into a hierarchical system with the final product (such as patient care) at the lowest level and with support and overhead activities at successively higher levels. Subsequently, the aggregate costs by category were allocated to final activities in a step-wise fashion using simultaneous equation techniques [[24], Ch. 4] and the development of allocation criteria reflecting actual resource use. At the end of the standard step-down costing procedure, all costs of a study site had been distributed to the final service departments so that an average costs figure could be calculated by dividing the number of services provided by individual departments. Micro-costing techniques [27] were used to supplement the above information in order to achieve information on interventions against individual diseases. For instance, a review of a sample of inpatient notes was performed at hospitals in order to capture the treatment pattern of the most common health problems. With respect to the treatment of the less common health problems, official treatment guidelines were used [23]. 
Having finalised the study activities described above, unit costs of individual curative and preventive services were available for the study sites included.

\section{Costs of interventions at population level}

Unit costs of individual health interventions estimated from data collected at the study sites were utilised for calculating the total costs of offering this service for a population group as a whole. This was done to take account of the fact that costs and effects measured in DALYs averted depended on age of onset of disease. The total costs of a specific curative health intervention were calculated for a hypothetical district population of 250,000 individuals in Zimbabwe with the same age and sex distribution and incidence of diseases as the country as a whole. The number of treatments for each disease was determined by incidence and the health seeking behaviour of the population. Information on incidence of diseases was drawn from a national study which provided estimates of new cases of disease by age and sex groups for the year 1997 [18]. In addition, the proportions of cases by disease likely to seek treatment were determined based on advice from clinical experts as well as the National Health Information System [19]. Using these two types of information, the total number of treatments by age and sex could be estimated for each disease under study. Subsequently, the total costs of a curative health intervention were estimated by multiplying this number with the relevant unit costs:

$$
C^{j}=U^{j} \sum_{a} \sum_{s} I_{a s}^{j} H_{a s}^{j}
$$

where $C^{j}$ is the population level costs of intervention $j, U^{j}$ indicates the unit costs of curative health intervention $j$. In addition, $I_{a s}^{j}$ is the absolute, annual number of incident cases of a health problem (which may be treated by intervention $j$ ) in population group of age $a$ and sex $s$ while $H_{a s}^{j}$ is the proportion of incident cases seeking treatment in the same population group. Outpatient services were offered both at health centres and hospitals. It was assumed that $80 \%$ of all cases were treated at health centres and $20 \%$ at district hospital outpatient departments corresponding to the actual health seeking behaviour [19]. Some health problems required life long treatment like for instance insulin-dependent diabetes. In these cases, the specific cost figures estimated for a given length of time were recalculated to match the life expectancies at various ages of onset of the disease as indicated in the formula below:

$$
C^{j}=\sum_{a} \sum_{s} I_{a s}^{j} H_{a s}^{j} \sum_{t=1}^{T(a s)}\left[(1+r)^{-(t-1)} A_{t}^{j}\right]
$$

where $A_{t}^{j}$ is the annual costs at time $t$ for health intervention $j$ for a chronic condition while $T(a s)$ indicates the life expectancy of an individual belonging to population group of age $a$ and sex $s$. Future costs were discounted using a real discount rate $r$ of 3 percent.

The primary preventive interventions incurred costs at district and provincial health offices and typically also at the level of health providers such as health centres and hospitals. The pattern of cost components for preventive interventions therefore followed the general form:

$$
C^{j}=D^{j}+P^{j}+U^{j} \sum_{a} \sum_{s} M_{a s}^{j} N_{a s}^{j}
$$

where $D^{j}$ and $P^{j}$ represent the overall costs related to preventive intervention $j$ at the district and the particular district's share of the provincial office respectively. In addition, $U j$ denotes the unit costs of preventive activities such as vaccinations or STI treatments performed at health centres and hospital outpatient departments. Finally, $M_{a s}^{j}$ is the absolute number of individuals in population group of age $a$ and sex $s$ targeted for intervention $j$ and with $N_{a s}^{j}$ denoting the percentage actually covered. Information on the number of individuals in each age and sex group in the study population could be obtained from the most recent census $[28,29]$ and updating these figures using estimates of population growth [30]. Coverage of the five preventive health interventions was established through discussions with the responsible staff in the four districts. For some activities such as immunisation, information on coverage was collected as part of a recent Demographic and Health Survey [31].

\section{Estimation of effectiveness of interventions at population level}

The benefits of an intervention were measured as the reduction in the burden of disease (DALYs averted) as a result of the intervention. Following the Global Burden of Disease methodology [32-34], the burden of disease for an individual of sex $s$ dying prematurely at age $a, B O D_{a s^{\prime}}$ and with life expectancy $T$ (as) (or suffering from a disease episode starting at age $a$ with length $T(a s)$ ) could be calculated from the formula: 


$$
B O D_{a s}=\int_{t=a}^{a+T(a s)} W K t e^{-\beta t} e^{-r(t-a)} d t
$$

where $W$ is a quality adjustment factor (disability weight) representing different levels of health [[33,35]: Annex 3]. The component $\mathrm{Kte}^{-\beta t}$ is an age weighting curve of an inverted u-shape so that the relative value of life years in young adulthood is higher than in other ages while $e^{-r(t-a)}$ is the discount factor using discount rate $r=0.03$. Finally, rather than using actual life expectancies of the population under study, the DALY methodology employs long life expectancies from a low mortality model life table (Coale-Demeny West Level 26 [36]). Life expectancies $T(a s)$ therefore depend on both age and sex. The benefit in terms of DALYs gained from a successful intervention $j$ for a person of age $a$ and sex $s$ is calculated in the following way:

$$
\triangle B O D_{a s}^{j}=B O D_{a s}-B O D_{a s}^{j}
$$

where $B O D_{a s}^{j}$ is the burden of disease after a successful intervention. For instance, the number of DALYs gained for an individual dying prematurely at age $a_{1}$ without treatment but postponing death until age $a_{2}\left(a_{1}<a_{2}\right)$ following an intervention can be calculated using equation (5). A detailed explanation using worked examples of how to calculate DALYs for cost-effectiveness analysis has been presented by Fox-Rushby and Hanson [37].

Effectiveness of health interventions in a real world setting depend on a wide range of factors $[11,38]$. Four factors were identified for the present study as having an important influence on the effect of curative interventions: efficacy of individual drugs, diagnostic accuracy, appropriateness of the treatment prescribed and patient compliance.

With respect to efficacy, sources of information for this measure by type of drug were mainly a World Bank review [5], Cochrane systematic reviews (such as for instance trachoma [39]) or articles identified through the Cochrane register of randomized controlled trials. Very little hard evidence from the Zimbabwean setting could be found on the other three factors so estimates of these aspects were determined for each health problem based on discussions with clinical experts. In a similar fashion as applied by Evans et al. [13], the effectiveness of a health intervention was estimated by reducing the efficacy of the relevant drug by a factor between 0 and 1 . The benefits at population level in terms of DALYs averted of a specific curative health intervention $j$ were subsequently calculated as:

$$
D A L Y s^{j}=E^{j} B^{j} F^{j} G^{j} \sum_{a} \sum_{s} I_{a s}^{j} H_{a s}^{j} \Delta B O D_{a s}^{j}
$$

where $E^{j}, B^{j}, F^{j}$ and $G^{j}$ are efficacy of the drug prescribed, diagnostic accuracy, correct treatment and patient compliance respectively for curative intervention $j$ measured as percentages. Expressed in words, this equation estimates the number of individuals cured through treatment $j$ by excluding ineffective services from the total number of individuals seeking treatment and translating the resulting health benefits into DALYs averted.

A similar procedure was applied to preventive interventions involving first determining the effect under ideal conditions followed by adjusting this to incorporate real world conditions. Efficacy of malaria spraying was derived from a study in South Africa which compared the prevalence of malaria infection in sprayed areas and nonsprayed areas [40]. Similarly, efficacy estimates were derived for environmental health [41-43], food supplementation $[44]$, vaccines $[45,46]$ and STI syndromic management $[47,48]$. The number of DALYs averted at population level for a given preventive intervention $j$ was calculated as:

$$
D A L Y s^{j}=E^{j} R^{j} \sum_{a} \sum_{s} I_{a s}^{j} \Delta B O D_{a s}^{j}
$$

where $E^{j}$ is the efficacy of the intervention under ideal circumstances and $R^{j}$ is any necessary downward adjustment (less than perfect coverage) of efficacy while $I_{a s}^{j}$ is the incidence of disease in different age- and sex groups. Coverage of the five preventive health interventions was established through discussions with the responsible staff in the four districts included or in the case of EPI utilising the Demographic and Health Survey [31].

\section{Calculation of cost-effectiveness ratios}

Having estimated the total costs and effectiveness of various health interventions, the cost-effectiveness ratio for intervention $j, C E R^{j}$, was found as:

$$
C E R^{j}=\frac{C^{j}}{D A L Y s^{j}}
$$

where costs were estimated using equation (1), (2) or (3) and effects were estimated using (6) or (7).

\section{Development of essential health packages}

The selection of health interventions for essential health packages may be done by applying different sets of principles. According to the World Bank principles for develop- 
ing health packages [16], desirable health interventions are those with low cost-effectiveness ratios and at the same time address important health problems. Another possible set of principles is a pure cost-effectiveness criterion [49]. This entails utilising a process consisting of selecting first the intervention with the lowest cost-effectiveness ratio and then calculating the total costs of averting this health problem. The subsequent step chooses the intervention with the second lowest cost-effectiveness ratio and also calculating the total costs of averting this health problem and so on until the budget is exhausted.

Assuming that the cost-effectiveness ratios estimated for the health interventions of this study complied with the assumptions of perfect divisibility and constant returns to scale $[50,51]$, the total costs and effects in terms of disease reduction of various sets of interventions could be estimated. Median cost-effectiveness ratios were utilised for each type of intervention. Estimates of the burden of disease by cause which must be addressed by the selected interventions were obtained from a previous national study [18] and reproduced in Annex 1. It was further assumed that 300 millions of Zimbabwe dollars were available for the essential packages. This corresponded to just below 10 percent of actual capital and recurrent expenditure at the national level in the financial year 1997/1998. Two additional restrictions were imposed. First, the majority of diseases could not be averted at a single level of the health system. For instance, if an intervention against pneumonia was selected to be part of the package, this health problem could not be fully avoided by offering treatment through health centres. It would be necessary to offer hospital treatment as well. Secondly, it was assumed that at most 30 percent of the HIV burden could potentially be averted through the preventive intervention included in the study (STI treatment) to avoid the budget being exhausted by this single intervention.

\section{Sensitivity analysis}

The sensitivity of the cost-effectiveness ratios was assessed by varying important parameters and assumptions. Instead of a 3\% discount rate utilised for the baseline calculations of cost-effectiveness ratios, these were recalculated using discount rates of 6 and 10\%. Estimated time preferences with respect to life years vary a lot [52] although a recent empirical study in Tanzania suggested a time preference of a similar size to the range chosen above [53]. The size of the discount rate affected both the effects of health interventions through the DALY formula and the costs of health services. The long life expectancies from the chosen model life table were replaced by actual, period life expectancies as recommended in the recent World Bank health sector priorities review [12]. Much shorter, actual Zimbabwean life expectancies were estimated based on the population size and the number of deaths by age and sex obtained from the census of 1997 [30]. Furthermore, rather than the inverted u-shape of the age weighting function suggested by the DALY methodology, an age weighting function with an equal value of 1 on each life year was used as also suggested by the World Bank health sector priorities review [12]. Some of the health facilities visited operated considerably below full capacity during the study year thus pushing up costs of services. For the sensitivity analysis, cost-effectiveness ratios were recalculated under the assumption that all health facilities were moderately and significantly better utilised (e.g. 80 and $95 \%$ bed occupancy rates in inpatient departments respectively). Finally, assessing the robustness of the cost-effectiveness ratios to changes in the effectiveness of interventions was very important since this was an area with little hard evidence. Therefore, cost-effectiveness ratios were recalculated assuming a lower effectiveness of individual health interventions than in the baseline calculations. Calculations were performed utilising effectiveness estimates that were 90,70 and $50 \%$ of the baseline estimates.

\section{Results}

Combining the estimated costs and effects resulted in a list of costs per DALY averted for a large number of health interventions. Table 1 displays the range of costs per DALY of the health interventions included in this study. The specification of a range of costs for individual health interventions reflects the fact that the costs of individual treatments differed in the health facilities and the various preventive programmes due to such factors as varying treatment patterns for similar diseases, availability of resources, degree of capacity utilisation of health facilities and incidence of diseases.

Among the interventions with the lowest cost-effectiveness ratios, curative treatment at health centres and hospital outpatient departments of pneumonia, severe diarrhoeal diseases, peptic ulcer, dysentery, malaria, trachoma, schistosomiasis haematobium and glaucoma were identified. In addition, curative treatments for meningococcal meningitis, pneumonia and malaria at district and provincial hospitals were also in the group of interventions with low costs per DALY. Preventive interventions of low costs per DALY included improved STI treatment to avert new HIV infections and residual house spraying to avoid malaria infection. In the middle range of the list of costs per DALY averted, fewer interventions based at the first level of the delivery system were found. Treatment of scabies at health centres and hospital outpatient departments was the only exception. With respect to district and provincial hospitals, the treatment of dysentery, peptic ulcer, six months tuberculosis course, complicated deliveries with minor or major surgery (caesarean section) and appendectomy were estimated to have costs 
Table I: Costs per DALY in Z\$ by type of intervention (Z\$17 = US\$1), Zimbabwe, financial year 1997// 998

\begin{tabular}{|c|c|c|c|c|}
\hline \multirow[b]{2}{*}{ Disease group and intervention } & \multirow[b]{2}{*}{ Level of delivery } & \multicolumn{3}{|c|}{----- Costs per DALY ----- } \\
\hline & & Median & Lowest & Highest \\
\hline \multicolumn{5}{|l|}{ HIV } \\
\hline Prevention through access to treatment for STIs & Vertical programme & 129 & 124 & 133 \\
\hline Prophylaxis to prevent opportunistic diseases & District hospital, health centres & 9,959 & 9,712 & 11,063 \\
\hline Prophylaxis to prevent opportunistic diseases & Provincial hospital, health centres & 12,473 & 11,257 & 13,777 \\
\hline \multicolumn{5}{|l|}{ MALARIA } \\
\hline Treatment as an outpatient & Health centres, hospitals & 159 & 127 & 214 \\
\hline Treatment as an inpatient & District hospital & 173 & $|4|$ & 257 \\
\hline Prevention through residual house spraying & Vertical programme & 185 & 81 & 466 \\
\hline Treatment as an inpatient & Provincial hospital & 287 & 225 & 327 \\
\hline \multicolumn{5}{|l|}{ PNEUMONIA } \\
\hline Treatment as an outpatient & Health centres, hospitals & 42 & 35 & 53 \\
\hline Treatment as an inpatient & District hospital & 130 & 102 & 182 \\
\hline Treatment as an inpatient & Provincial hospital & 295 & 258 & 317 \\
\hline \multicolumn{5}{|l|}{ DIARRHOEAL DISEASES } \\
\hline Treatment an outpatient & Health centres, hospitals & 70 & 52 & 102 \\
\hline Prevention through hygiene promotion & Vertical programme & $|, 0| \mid$ & 985 & 1,054 \\
\hline \multicolumn{5}{|l|}{ DYSENTERY } \\
\hline Treatment as an outpatient & Health centres, hospitals & 85 & 77 & 102 \\
\hline Treatment as an inpatient & District hospital & 531 & 461 & 757 \\
\hline Treatment as an inpatient & Provincial hospital & 908 & 814 & 1,002 \\
\hline \multicolumn{5}{|l|}{ TUBERCULOSIS } \\
\hline Six months treatment with DOTS & District hospital, health centres & 815 & 706 & 878 \\
\hline Six months treatment with DOTS & Provincial hospital, health centres & 973 & 907 & 1,085 \\
\hline \multicolumn{5}{|l|}{ MALNUTRITION } \\
\hline Surveillance and targeted food supplementation & Vertical programme & 1,489 & $\mathrm{I}, 457$ & 1,524 \\
\hline \multicolumn{5}{|l|}{ MENINGITIS } \\
\hline Treatment as an inpatient (bacterial men.) & District hospital & 281 & 266 & 408 \\
\hline Treatment as an inpatient (bacterial men.) & Provincial hospital & 488 & 404 & 580 \\
\hline Treatment as an inpatient (meningococcal men.) & District hospital & 98 & 89 & 144 \\
\hline Treatment as an inpatient (meningococcal men.) & Provincial hospital & 176 & 147 & 208 \\
\hline \multicolumn{5}{|l|}{ PELVIC INFLAMMATORY DISEASE } \\
\hline Treatment as an outpatient & Health centres, hospitals & 365 & 346 & 411 \\
\hline Treatment as an inpatient & District hospital & 3,666 & 3,083 & 4,286 \\
\hline Treatment as an inpatient & Provincial hospital & 5,362 & $3,|8|$ & 7,543 \\
\hline \multicolumn{5}{|l|}{ SYPHILIS } \\
\hline Treatment as an inpatient & District hospital & 3,725 & 3,429 & $4,5 \mid 4$ \\
\hline Treatment as an inpatient & Provincial hospital & 7,612 & 6,263 & 9,126 \\
\hline \multicolumn{5}{|l|}{ URETHRAL DISCHARGE IN MALE } \\
\hline Treatment as an outpatient & Health centres, hospitals & 13,390 & 12,599 & 15,277 \\
\hline \multicolumn{5}{|l|}{ VAGINAL DISCHARGE } \\
\hline Treatment as an outpatient & Health centres, hospitals & 3,495 & 3,312 & 3,955 \\
\hline \multicolumn{5}{|l|}{ CHILDHOOD CLUSTER DISEASES } \\
\hline Prevention through vaccination & Vertical programme & 586 & 506 & 700 \\
\hline \multicolumn{5}{|l|}{ SCHISTOSOMIASIS HAEMATOBIUM } \\
\hline Treatment as an outpatient & Health centres, hospitals & 259 & 160 & 317 \\
\hline
\end{tabular}


Table I: Costs per DALY in Z\$ by type of intervention (Z\$I7 = US\$I), Zimbabwe, financial year 1997/I 998 (Continued)

\section{SCHISTOSOMIASIS MANSONI}

Treatment as an outpatient

TRACHOMA

Treatment as an outpatient

BACTERIAL CONJUNCTIVITIS

Treatment as an outpatient

\section{GLAUCOMA}

Treatment as an inpatient

Treatment as an inpatient

MINOR COMPLICATIONS IN DELIVERY

Surgery

Surgery

MAJOR COMPLICATIONS IN DELIVERY

Surgery (caesarean section)

Surgery (caesarean section)

\section{APPENDICITIS \\ Surgery \\ Surgery \\ INGUINAL HERNIA \\ Surgery \\ Surgery}

\section{ABSCESS ON EXTREMITY}

Surgery

Surgery

\section{DIABETES MELLITUS}

Inpatient stay and follow-up at health centres

Inpatient stay and follow-up at health centres

\section{HYPERTENSION}

Inpatient stay and follow-up at health centres

Inpatient stay and follow-up at health centres

\section{RHEUMATIC FEVER}

Inpatient stay and follow-up at health centres

Inpatient stay and follow-up at health centres

\section{GASTRITIS}

Treatment as an outpatient

Treatment as an inpatient

Treatment as an inpatient

\section{PEPTIC ULCER}

Treatment as an outpatient

Treatment as an inpatient

Treatment as an inpatient

\section{GASTROENTERITIS}

Treatment as an outpatient

Treatment as an inpatient

Treatment as an inpatient

\section{SCABIES}

Treatment as an outpatient
Health centres, hospitals

431

267

528

Health centres, hospitals

154

150

Health centres, hospitals

235

219

District hospital

Provincial hospital

District hospital

Provincial hospital

District hospital

Provincial hospital

District hospital

Provincial hospital

District hospital

Provincial hospital

District hospital

Provincial hospital

District hospital, health centres

Provincial hospital, health centres

District hospital, health centres

Provincial hospital, health centres

District hospital, health centres

Provincial hospital, health centres

Health centres, hospitals

District hospital

Provincial hospital

Health centres, hospitals

District hospital

Provincial hospital

Health centres, hospitals

District hospital

Provincial hospital

Health centres, hospitals

$\begin{array}{lll}211 & 160 & 342 \\ 419 & 340 & 508\end{array}$

$\begin{array}{lll}515 & 408 & 717\end{array}$

$\begin{array}{lll}757 & 443 \quad 1,072\end{array}$

$771 \quad 591 \quad 1,214$

$935 \quad 621 \quad 1,249$

$606 \quad 531 \quad 1,136$

$\begin{array}{lll}1,007 & 757 & \mathrm{I}, 138\end{array}$

$314 \quad 201 \quad 610$

$562 \quad 557 \quad 567$

$\begin{array}{lll}954 & 837 & \mathrm{I}, 796\end{array}$

I,555 I, I75 I,76I

$4,999 \quad 4,88 I \quad 5,330$

$5,157 \quad 4,749 \quad 5,565$

$8,510 \quad 8,419 \quad 9,032$

$9,732 \quad 9,094 \quad 10,370$

$3,241 \quad 3,012 \quad 3,387$

$3,935 \quad 3,777 \quad 4,093$

$\begin{array}{lll}394 & 362 & 461\end{array}$

$1,292 \quad \mathrm{I}, 203 \quad 2,007$

$\begin{array}{lll}2,465 & 1,999 & 2,989\end{array}$

$\begin{array}{rrr}95 & 75 & 130 \\ 428 & 397 & 684 \\ 850 & 686 & 1,036\end{array}$

$\begin{array}{rrr}331 & 279 & 425 \\ 895 & 830 & 1,287 \\ 1,545 & 1,295 & 1,825\end{array}$

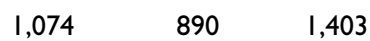


Table I: Costs per DALY in Z\$ by type of intervention (Z\$I7 = US\$I), Zimbabwe, financial year 1997/I 998 (Continued)

\begin{tabular}{|c|c|c|c|c|}
\hline \multicolumn{5}{|l|}{ IMPETIGO } \\
\hline Treatment as an outpatient & Health centres, hospitals & 15,745 & 13,256 & 20,249 \\
\hline \multicolumn{5}{|l|}{ BODY RINGWORM } \\
\hline Treatment as an outpatient & Health centres, hospitals & 17,266 & 13,920 & 23,130 \\
\hline \multicolumn{5}{|l|}{ TONSILLITIS } \\
\hline Treatment as an outpatient & Health centres, hospitals & 53,087 & 49,429 & 61,289 \\
\hline
\end{tabular}

per DALY averted in the middle range. Hygiene promotion in the community to prevent diarrhoea was also in the middle range at costs per DALY averted of $Z \$ 1,011$. The least cost-effective interventions of the list incorporated only health facility-based curative interventions. Health centre and hospital outpatient department interventions incorporated treatment for urethral discharge in males, body ringworm, impetigo and tonsillitis. The reasons for the high costs of these interventions were that these conditions were mild, often self-resolving and the treatment was in some cases not very effective due to low efficacy of the drug recommended. At hospitals, treatment interventions aimed at insulin-dependent diabetes, prophylaxis to avert opportunistic infections in HIV/AIDS patients, hypertension, pelvic inflammatory disease and syphilis were estimated to have high costs per DALY.

The estimated cost-effectiveness ratios were utilised to develop a package of health interventions by applying the World Bank criteria for selection of essential activities (cost-effective and addressing important health problems). As displayed in Table 2, these criteria suggested a variety of health interventions aimed at relieving and averting the health problems due to HIV, pneumonia, diarrhoeal diseases, protein-energy-malnutrition, meningitis, malaria, complicated deliveries and tuberculosis. Potentially, these interventions could avert 26.4 percent of the burden of disease in 1997 at total costs of $Z \$ 300$ million. The above calculations indicated that relatively few additional resources could address a large percentage of the present burden of disease.

Using instead a selection procedure based on a pure costeffectiveness criterion resulted in the interventions displayed in Table 3. Inclusion of health interventions for this package was continued until the total costs were at an identical expenditure level as the package described above. Interventions addressing important health problems like HIV, pneumonia, diarrhoeal diseases, malaria, tuberculosis and complicated deliveries were included in this package as was the case of the package described above. However, instead of including supplementary feeding against malnutrition, this package included relatively minor health problems like bacterial conjunctivitis, gastritis, childhood cluster diseases, glaucoma, peptic ulcer, schistosomiasis and trachoma. The total package could potentially avert a slightly higher share of the 1997 disease burden than the above package (27.2 versus 26.4 percent).

Generally, the cost-effectiveness ratios presented in the tables suggested that there was a good potential for improving the allocative efficiency in the public health care sector of Zimbabwe. Four general strategies could be

Table 2: Burden of disease averted and total costs of a package of health interventions selected based on cost-effectiveness and relative importance of disease criteria, Zimbabwe, financial year 1997/1998

\begin{tabular}{|c|c|c|c|c|}
\hline Disease group & Intervention & Level of delivery & $\begin{array}{l}\% \text { of } 1997 \text { disease } \\
\text { burden averted }\end{array}$ & $\begin{array}{l}\text { Total costs in } \\
\text { millions of } Z \$\end{array}$ \\
\hline HIV & Prevention & Vertical programme & 14.6 & 93.1 \\
\hline Pneumonia & Treatment & Outpatient care, inpatient care & 2.7 & 19.1 \\
\hline Diarrhoeal diseases & Treatment & Outpatient care & 2.4 & 8.5 \\
\hline Malaria & $\begin{array}{l}\text { Treatment/ } \\
\text { prevention }\end{array}$ & $\begin{array}{l}\text { Outpatient care, inpatient care, } \\
\text { vertical programme }\end{array}$ & 1.8 & 16.0 \\
\hline Tuberculosis & Treatment & Inpatient care, DOTS & 1.6 & 51.9 \\
\hline Complicated delivery & Treatment & Inpatient care & 1.0 & 35.1 \\
\hline Meningitis & Treatment & Inpatient care & 0.9 & 12.3 \\
\hline Dysentery & Treatment & Outpatient care, inpatient care & 0.7 & 17.8 \\
\hline Protein-energy malnutrition & Prevention & Vertical programme & 0.6 & 46.2 \\
\hline Total & & & 26.4 & 300.0 \\
\hline
\end{tabular}


Table 3: Burden of disease averted and total costs of a package of health interventions selected based on a pure cost-effectiveness criterion, Zimbabwe, financial year 1997/1998

\begin{tabular}{|c|c|c|c|c|}
\hline Disease group & Intervention & Level of delivery & $\begin{array}{l}\% \text { of } 1997 \text { disease } \\
\text { burden averted }\end{array}$ & $\begin{array}{r}\text { Total costs } \\
\text { in millions of } Z \$\end{array}$ \\
\hline HIV & Prevention & Vertical programme & 14.6 & 93.1 \\
\hline Pneumonia & Treatment & Outpatient care, inpatient care & 2.7 & 19.1 \\
\hline Diarrhoeal diseases & Treatment & Outpatient care & 2.4 & 8.5 \\
\hline Malaria & $\begin{array}{l}\text { Treatment/ } \\
\text { prevention }\end{array}$ & $\begin{array}{l}\text { Outpatient care, inpatient care, } \\
\text { vertical programme }\end{array}$ & 1.8 & 16.0 \\
\hline Tuberculosis & Treatment & Inpatient care, DOTS & 1.4 & 45.3 \\
\hline Meningitis & Treatment & Inpatient care & 0.9 & 12.3 \\
\hline Dysentery & Treatment & Outpatient care, inpatient care & 0.7 & 17.8 \\
\hline Complicated delivery & Treatment & Inpatient care & 0.5 & 15.5 \\
\hline Gastritis & Treatment & Outpatient care, inpatient care & 0.4 & 24.9 \\
\hline Trachoma & Treatment & Outpatient care & 0.4 & 2.7 \\
\hline Glaucoma & Treatment & Inpatient care & 0.4 & 4.8 \\
\hline Gastroenteritis & Treatment & Outpatient care, inpatient care & 0.3 & 15.7 \\
\hline Inguinal hernia & Treatment & Inpatient care & 0.1 & 2.7 \\
\hline Childhood cluster & Prevention & Vertical programme & 0.1 & 3.9 \\
\hline Peptic ulcer & Treatment & Outpatient care, inpatient care & 0.1 & 2.8 \\
\hline Pelvic inflam. disease & Treatment & Outpatient care, inpatient care & 0.1 & 9.6 \\
\hline Appendicitis & Treatment & Inpatient care & 0.1 & 3.4 \\
\hline Bacterial conjunctivitis & Treatment & Outpatient care & 0.1 & 1.0 \\
\hline Schistosomiasis & Treatment & Outpatient care & 0.1 & 1.0 \\
\hline Total & & & 27.2 & 300.0 \\
\hline
\end{tabular}

outlined. Firstly, there were great differences in the estimated cost-effectiveness ratios placed at the top and at the bottom end of the cost per DALY league table for Zimbabwe (Table 1). In principle, therefore, substantial improvements in the allocative efficiency could be achieved by a reallocation of resources from the interventions with high cost-effectiveness ratios to interventions with low cost-effectiveness ratios. Secondly, it appeared beneficial to put particular attention to a narrow range of interventions with low cost-effectiveness ratios. The calculations behind the development of the two intervention packages (Tables 2 and 3 ) indicated that as much as one quarter of the total burden of disease could be averted by focusing on a few interventions at a level of total costs corresponding to ten percent of the current, national expenditure at that time. Thirdly, the cost-effectiveness figures estimated also confirmed the findings of other studies (e.g. $[54,55])$ namely that for the same disease, it was more attractive from an efficiency point of view to have the health problem taken care of at the lowest level of the referral system as possible. Comparing the cost-effectiveness ratios for the same health problem, the highest ratios were generally found in provincial hospitals followed by district level hospitals and outpatient care. According to calculations not presented in Table 1, cost-effectiveness ratios at health centres were also lower than hospital outpatient departments. In other words, this suggested that there could be substantial gains from utilising the public health care sector facilities in the hierarchical manner that was intended (e.g. only treating difficult health problems at high level facilities and mild cases at the lowest levels). Fourthly, there appeared to be a potential for designing very cost-effective preventive health interventions at the expense of curative interventions. The estimated costs per DALY for five preventive health programmes included in this study were all relatively low.

The sensitivity analysis presented in Table 4 suggested that increasing the discount rate to $6 \%$, utilising the actual Zimbabwean life expectancies, applying equal age weighting or assuming a better capacity utilisation of health facilities had relatively minor effects on the cost-effectiveness ratios. As compared to the baseline estimates of Table 1 , these assumptions resulted in a difference in costs per DALY of less than $20 \%$ for the majority of the 65 interventions included in the study. In addition, the majority of interventions had shifted their rank by three places or less in the rank order of interventions by cost-effectiveness ratio. Contrary to these observations, utilising a higher discount rate of $10 \%$ had more profound effects on the figures. Cost-effectiveness ratios of most interventions rose by $30 \%$ or more and the rank changed by four steps and above for 24 interventions. Reducing the estimates of effectiveness in individual health interventions, the rank of health interventions was more strongly affected at sufficiently large decreases in intervention effectiveness. For instance, if intervention effectiveness was $50 \%$ of the original estimates, more than half the interventions decreased 
Table 4: Influence of selected assumptions and parameters on the level of cost-effectiveness ratios and the rank order of interventions by cost-effectiveness ratios as compared to baseline estimates

\begin{tabular}{|c|c|c|c|c|c|c|c|c|}
\hline \multirow[t]{2}{*}{$\begin{array}{l}\text { Assumption or } \\
\text { parameter investigated }\end{array}$} & \multicolumn{4}{|c|}{$\begin{array}{l}\text { Difference in costs per DALY } \\
\text { as compared to baseline } \\
----- \text { change in percent }\end{array}$} & \multicolumn{4}{|c|}{$\begin{array}{l}\text { Difference in rank order } \\
\text { as compared to baseline } \\
\text {---- places up or down ------ }\end{array}$} \\
\hline & $0-10$ & $10-20$ & $20-30$ & $\geq 30$ & $0-1$ & $2-3$ & $4-5$ & $\geq 6$ \\
\hline & \multicolumn{4}{|c|}{---- Number of interventions ---- } & \multicolumn{4}{|c|}{---- Number of interventions ---- } \\
\hline Discount rate $6 \%$ & 55 & 0 & 4 & 6 & 47 & 13 & 3 & 2 \\
\hline Discount rate $10 \%$ & 8 & 3 & 2 & 52 & 25 & 16 & 15 & 9 \\
\hline Zimbabwean life expectancies & 20 & 38 & 3 & 4 & 57 & 7 & I & 0 \\
\hline Equal value on each life year & 11 & 34 & 14 & 6 & 45 & 18 & I & I \\
\hline Capacity utilisation $80 \%$ & 43 & 11 & 10 & 1 & 41 & 21 & 3 & 0 \\
\hline Capacity utilisation $95 \%$ & 19 & 20 & 14 & 12 & 32 & 28 & 4 & I \\
\hline Effectiveness $90 \%$ of baseline & 2 & 63 & 0 & 0 & 41 & 21 & 3 & 0 \\
\hline Effectiveness $70 \%$ of baseline & 0 & 0 & 2 & 63 & 8 & 22 & 19 & 16 \\
\hline Effectiveness $50 \%$ of baseline & 0 & 0 & 0 & 65 & 5 & 9 & 10 & 41 \\
\hline
\end{tabular}

Note: The median costs per DALY utilising an alternative assumption or parameter were compared to the median costs of Table I. Likewise, the rank order of interventions by median cost-effectiveness ratios utilising an alternative assumption or parameter were compared to the rank order of Table I.

their ranks by more than five places. In particular, the ranks of hospital treatment of bacterial meningitis, malaria, pneumonia, tuberculosis and surgical interventions as well as health centre treatment of conjunctivitis, schistosomiasis haematobium and gastroenteritis were sensitive to changes in intervention effectiveness.

\section{Discussion}

\section{Limitations of the approach applied in Zimbabwe}

The above findings must be seen in the light of the limitations of the study. As a starting point, the cost function assumed for this study was simple and restrictive. The assumptions of constant returns to scale and perfect divisibility ensured that the average costs per unit of health of any given health intervention were the same irrespective of the level of production. These assumptions facilitated the identification of which interventions should go into an essential health package as well as the exact level of health services production necessary to eliminate the disease burden of a health problem. While there may be several reasons for deeming these assumptions unrealistic, they are frequently applied both for curative and preventive interventions [56-58]. Relieving the assumptions of constant returns to scale and perfect divisibility to develop cost functions with non-constant unit costs and limited possible production levels would require more complicated optimising techniques such as linear, non-linear or integer programming $[59,60]$.

Much of the information necessary for costing of health interventions was available in principle in the sense that the majority of health facilities and vertical programmes visited kept a good record of most of the resources used although only at an aggregate level (i.e. total resources for a whole hospital and not broken down by diagnosis). However, the costing exercise was nevertheless in some aspects not as detailed and extensive as could have been desired mainly as a result of limited research resources. First, a relatively limited number of health centres, hospitals and preventive activities in districts were included as study sites leading to a risk of not capturing a representative pattern of unit costs for the country as a whole. Second, the costing methodology also involved a number of simplifying assumptions in the data collection at study sites including, for instance, that the average personnel and other costs per inpatient day were the same irrespective of the diagnosis of a patient and that the treatment of most conditions followed the treatment guidelines [23] rather than the pattern found through the micro-costing data collection. Third, the number of health interventions included was relatively low due in particular to problems of identifying sufficient information to estimate effectiveness of interventions.

Perhaps the most serious limitation was the scarcity of evidence on effectiveness of health interventions and of health systems research in Zimbabwe. The observations made by several authors $[14,61,62]$ that we desperately lack data on these aspects are therefore also very relevant for the Zimbabwean situation. Research on factors influencing how health interventions work in the real world was extremely limited. One example of an extremely useful piece of research for the purposes of the present study was the finding of Vundule and Mharakurwa [63] that as 
many as 21 percent of villagers might refuse access of spraying teams to some rooms during residual house spraying. For the present study, the necessary information required to estimate effectiveness was for the majority of health interventions based on best guesses by clinical experts.

\section{Operational lessons learned}

The present exercise replicated the methods underlying the 1993 World Development Report [16] and utilised also in more recent analyses [6]. The Zimbabwean research proved very data intensive and most of the needed information to determine the burden of disease, costs and effects of health interventions was not immediately available which required very extensive data collection in the field. Results presented here as well as the burden of disease estimates published previously [18] represented what was feasible within the time and resources allocated. The net time of work for this research was approximately one and a half year with one researcher, a study administrator and eight research assistants working full time and a core team of ten researchers and civil servants from selected ministries working on a part-time basis (3-6 hours per individual per week on average). Despite this substantial resource input, it was deemed necessary to adopt a number of simplifying assumptions and less extensive data collection activities some of which have been discussed above.

Substantial efforts were invested in searching for published and unpublished studies on the effectiveness of health interventions as well as health systems research on how health interventions operated in reality in Zimbabwe. The lack of knowledge was a main obstacle to this study and came to some extent as a surprise to research team. If this situation had been anticipated, the data collection would have focused more on collecting additional information on the functioning of the health system which could subsequently have been utilised to adjust the findings from efficacy studies measuring impact under ideal conditions to arrive at estimates of effectiveness for the Zimbabwean situation. Efficacy studies from similar settings in Africa are more plentiful [i.e. [64,65]]. One example of a possible useful piece of health systems research would be a review of the health centres of this study to investigate the compliance of tuberculosis patients on directly observed treatment short course (DOTS).

The characteristics described above had as a consequence that it was possible to include only a limited number of interventions for the cost-effectiveness analysis. In other words, cost-effectiveness assessments were not performed for a whole range of relevant interventions. For instance, interventions directed at health problems with a signifi- cant burden of disease such as depression and anxiety disorders and road traffic accidents were not included. Preventive interventions were incorporated only in a limited number so that many common HIV preventive activities were left out of the analysis including condom promotion, voluntary testing and counselling, peer-based programmes to educate high risk groups and prevention of mother-to-child transmission but also preventive activities against non-communicable diseases and injuries. As a result of these shortcomings, it is not possible to conclude that we have now identified the best or the most efficient essential package of care which must be focused on for many years. There may be other more efficient packages since it is possible only able to make conclusions with regards to reallocations among the interventions investigated in this study. The present endeavour may more appropriately be seen as just one possible direction towards improving allocative efficiency in the health care sector.

Nevertheless, the present exercise was still extremely useful. It captured costs per DALY of a range of health interventions representing the situation in the health care sector at the time of study. Before this study, there was only very limited and scattered information on the costs and even less on the effects of health interventions [55,6668]. This study also demonstrated what was possible in a setting like Zimbabwe given a certain level of research resources but also that most of the limitations mentioned could in principle be overcome if more research resources were available. For instance, the cost data collection could have been extended and more health systems research could have been planned to inform the effectiveness component which could have enlarged the range of health interventions for the cost-effectiveness analysis. Finally, this study highlighted the most important gaps in the knowledge for priority setting i.e. the shortage of hard evidence on effectiveness of health services.

\section{Utilisation of results}

According to the health information system, acute respiratory infections, malaria and skin diseases are the most common health problems treated at outpatient department level whereas pulmonary tuberculosis (as much as $22 \%$ of all inpatient days in the country), malaria and pneumonia are the most frequent diagnoses in individuals admitted as inpatients at hospitals in 1998 [19]. Large proportions of pulmonary tuberculosis and pneumonia cases are probably caused by underlying HIV [18]. Most of these interventions have been deemed relatively costeffective in this study and are components of the packages suggested (Tables 2 and 3). However, the present study suggests that HIV prevention is more cost-effective than treatment (including TB treatment) which has been confirmed by other studies [69]. Also malaria prevention in 
high incidence areas appeared to have lower costs per DALY compared to treatment. The central level of Ministry of Health controls the overall allocation of funds between hospitals, where the majority of interventions are curative, and preventive programmes. It is therefore possible to change priorities at the macro level by shifting the balance in favour of the preventive component and furthermore to focus on HIV and malaria prevention. Apart from deciding the funds available for individual hospitals, the central level of Ministry of Health has less influence on the priority setting at health centre and hospital level where the interventions offered to a large extent are determined by self-referral of patients. Rationing decisions for treating different patient groups will be done by health practitioners and may involve a variety of considerations and values (see i.e. [70]) resulting in a focus which may differ from priority setting based on pure cost-effectiveness criteria. The present study pointed to a direction of focus among curative health interventions which may be difficult to enforce among health practitioners. Increased legitimacy and support among clinicians and other health sector personnel as well as patients may be secured if they are involved in the priority setting procedure through a consultative process where these groups are allowed to incorporate their own values. For instance, several authors have suggested that other criteria such as equity, severity of disease, age of patient groups and capacity to benefit may affect the rank order of health priorities in the opinion of health personnel [71-73].

\section{Conclusion}

The previous pages showed that it was feasible to conduct cost-effectiveness analyses for a large number of health interventions in a developing country like Zimbabwe using a consistent methodology similar to the analysis performed at a general, non-country specific level by the World Bank [16]. The analyses performed in Zimbabwe suggested that cost-effective health interventions were available for some of the major health problems including HIV, pneumonia, tuberculosis and malaria. In addition, the analysis suggested that there was substantial potential for improving the efficiency with which resources are utilised in the public health care sector.

Limitations to the approach applied in Zimbabwe were identified including short cuts in the costing methodology and scarcity of evidence on effectiveness of health interventions. As a result, important health interventions were not incorporated in the cost-effectiveness analysis. However, most of the obstacles identified in this study could in principle be overcome by adding more research resources. For instance, adding a large component of health systems research on the actual functioning of the health system would improve the effectiveness estimates and enable the inclusion of more health interventions in the cost-effec- tiveness analysis. A larger number of health interventions assessed by cost-effectiveness analysis would in addition make the subsequent identification of an essential package of health interventions more credible.

\section{Competing interests}

The authors declare that they have no competing interests.

\section{Authors' contributions}

KSH contributed substantially to the conception and design of the study, data collection in the field, analysis of the data and drafted the manuscript. GC contributed substantially to the conception and design of the study, data collection in the field, analysis of the data and critically reviewed the manuscript. All authors read and approved the final manuscript.

\section{Annex 1}

See Table 5.

Table 5: Annex I: Total burden of disease as measured by Disability-Adjusted Life Years (DALYs) and distribution by the top 25 underlying causes, Zimbabwe, 1997

Total DALYs $4,948,172$

\section{CaIV}

Depression and anxiety disorders

Diarrhoeal diseases

Low birth weight

Lower respiratory tract infections $\quad 3.3$

Birth asphyxia and birth trauma $\quad 2.7$

Protein-energy malnutrition $\quad 2.3$

Malaria

Tuberculosis

Road traffic accidents

STIs excluding HIV

Iron-deficiency anaemia

Bacterial meningitis

Maternal sepsis

Sense organ diseases

Self-inflicted injuries

0.7

Alcohol dependence $\quad 0.6$

Rheumatic heart disease $\quad 0.6$

Obstructed labour $\quad 0.5$

Hypertensive heart disease $\quad 0.5$

Diabetes mellitus $\quad 0.5$

Asthma $\quad 0.5$

Inflammatory heart disease $\quad 0.5$

$\begin{array}{ll}\text { All other conditions } & 15.8\end{array}$

Source: [18]. 


\section{Acknowledgements}

The present study was part of a larger research project on "The National Burden of Disease and Cost-Effectiveness of Health Services in Zimbabwe" conducted under the general direction of a steering committee consisting of the following individuals in addition to the authors (position and institution at the time of the study in brackets): Jens Byskov (DANIDA advisor, Ministry of Health and Child Welfare, Zimbabwe), Rickson Gunzo (statistician, Central Statistical Office and Ministry of Health and Child Welfare, Zimbabwe), Jennifer Jelsma (senior lecturer, Department of Rehabilitation, University of Zimbabwe, Zimbabwe), David Matanhire (medical research officer, Blair Research Institute, Zimbabwe), Chiratidzo Ndhlovu (senior lecturer, Department of Medicine, University of Zimbabwe, Zimbabwe), Bruno Piotti (epidemiologist, Ministry of Health and Child Welfare, Zimbabwe), Godfrey Woelk (senior lecturer, Department of Community Medicine, University of Zimbabwe, Zimbabwe) and Citshela Makore (study administrator, Ministry of Health and Child Welfare, Zimbabwe). In addition, the following persons served as consultants to the study: Deborah Bradshaw (South African Medical Research Council, South Africa), Kristina Nkomo (Bulawayo City Health Department, Zimbabwe) and Theo Vos (Public Health Division, Department of Human Services, Victoria, Australia).

The study was funded by Danish International Development Agency (DANIDA) and the Department for International Development (DFID).

We thank Ulrika Enemark, Lars Peter $\varnothing$ sterdal and two anonymous reviewers for helpful comments and suggestions to the paper.

\section{References}

I. Maynard A: Developing the health care market. Econ J I99I, I0I:1277-I286.

2. Birkett DJ, Mitchell AS, McManus P: A cost-effectiveness approach to drug pricing in Australia. Health Affairs 200I, 20:I04-II4.

3. Kitzhaber JA: Prioritising health services in an era of limits: the Oregon experience. BMJ 1993, 307:373-377.

4. Talmor D, Shapiro N, Greenberg D, Stone PW, Neumann PJ: When is critical care medicine cost-effective? A systematic review of the cost-effectiveness literature. Crit Care Med 2006, 34:2738-2747.

5. Jamison DT, Mosley WH, Measham AR, Bobadilla JL, Eds: Disease control priorities in developing countries New York: Oxford University Press; 1993.

6. Jamison DT, Breman JG, Measham AR, Alleyne G, Claeson M, Evans DB, Jha P, Mills A, Musgrove P, Eds: Disease control priorities in developing countries 2nd edition. New York: Oxford University Press; 2006.

7. Laxminarayan R, Chow J, Shahid-Salles SA: Intervention cost-effectiveness: overview of main messages. In Disease control priorities in developing countries 2 nd edition. Edited by: Jamison DT, Breman JG, Measham AR, Alleyne G, Claeson M, Evans DB, Jha P, Mills A, Musgrove P. New York: Oxford University Press; 2006:35-86.

8. Hutubessy R, Chisholm D, Tan Torres-Edejer T, WHO-CHOICE: Generalized cost-effectiveness analysis for national-level priority-setting in the health sector. Cost Eff Resour Alloc 2003, 1:8.

9. Adam T, Evans DB, Murray CJL: Econometric estimation of country-specific hospital costs. Cost Eff Resour Alloc 2003, I:3.

10. Johns B, Baltussen R, Hutubessy R: Programme costs in the economic evaluation of health interventions. Cost Eff Resour Alloc 2003, I:I.

II. Jha P, Bangoura $O$, Ranson $K$ : The cost-effectiveness of forty health interventions in Guinea. Health Policy Plan 1998, 13:249-262.

12. Musgrove P, Fox-Rushby J: Cost-effectiveness analysis for priority setting. In Disease control priorities in developing countries 2 nd edition. Edited by: Jamison DT, Breman JG, Measham AR, Alleyne G, Claeson M, Evans DB, Jha P, Mills A, Musgrove P. New York: Oxford University Press; 2006:27I-285.
13. Evans DB, Tan-Torres Edejer T, Adam T, Lim SS: Achieving the millennium development goals for health: methods to assess the costs and health effects of interventions for improving health in developing countries. BMJ 2005, 33 I: I I37- I 40.

14. Williams A: Calculating the global burden of disease: time for a strategic reappraisal? Health Econ 1999, 8: I-8.

15. Kumaranayake L, Walker D: Cost-effectiveness analysis and priority-setting: global approach without meaning? In Health policy in a globalising world Edited by: Lee K, Buse K, Fustukian S. Cambridge: Cambridge University Press; 2002: I40- 156.

16. World Bank: World Development Report 1993: investing in health New York: Oxford University Press; 1993.

17. Bobadilla JL, Cowley P, Musgrove P, Saxenian H: Design, content and financing of an essential national package of health services. In Global comparative assessments in the health sector: disease burden, expenditures and intervention packages Edited by: Murray CJL, Lopez AD. Geneva: World Health Organization; 1994:17I-180.

18. Chapman G, Hansen KS, Jelsma J, Ndhlovu C, Piotti B, Byskov J, Vos $\mathrm{T}$ : The Burden of Disease in Zimbabwe in 1997 as measured by Disability-Adjusted Life Years lost. Trop Med Int Health 2006, I I: $667-678$

19. Ministry of Health and Child Welfare: Zimbabwe national health profile 1998 Harare: Government of Zimbabwe, National Health Information and Surveillance Unit; 1999.

20. United Nations Development Programme: Human Development Report 1998 Zimbabwe Harare: United Nations Development Programme, Zimbabwe, Poverty Reduction Forum, Government of Zimbabwe, Institute of Development Studies, University of Zimbabwe; 1998.

21. Economist Intelligence Unit: Country profile Zimbabwe 2008 London: Economist Intelligence Unit; 2008.

22. World Bank: Zimbabwe. Financing health services Washington, D.C.: The World Bank; 1992

23. Ministry of Health and Child Welfare: EDLIZ - fourth essential drugs list and standard treatment guidelines for Zimbabwe Harare: Government of Zimbabwe, Directorate of Pharmacy Services; 2000.

24. Drummond MF, Sculpher MJ, Torrance GW, O'Brien B, Stoddart GL, Eds: Methods for the economic evaluation of health care programmes 3rd edition. Oxford: Oxford University Press; 2005.

25. Walker D, Kumaranayake L: Allowing for differential timing in cost analyses: discounting and annualization. Health Policy Plan 2002, 17: II2-II8.

26. Conteh L, Walker D: Cost and unit cost calculations using stepdown accounting. Health Policy Plan 2004, 19:127-135.

27. Luce BR, Manning WG, Siegel JE, Lipscomp J: Estimating costs in cost-effectiveness analysis. In Cost-effectiveness in health and medicine Edited by: Gold MR, Siegel JE, Russell LB, Weinstein MC. New York: Oxford University Press; 1996:176-213.

28. Central Statistical Office: Census 1992. Provincial profile, Midlands Harare: Government of Zimbabwe; 1994.

29. Central Statistical Office: Census 1992. Provincial profile, Manicaland Harare: Government of Zimbabwe; 1994.

30. Central Statistical Office: Zimbabwe 1997 inter-censal demographic survey report Harare: Government of Zimbabwe; 1998.

31. Central Statistical Office [Zimbabwe] and Macro International Inc.: Zimbabwe Demographic and Health Survey 1999 Calverton: Macro International Inc.; 2000.

32. Murray CJL: Quantifying the burden of disease: the technical basis for disability-adjusted life years. In Global comparative assessments in the health sector: disease burden, expenditures and intervention packages Edited by: Murray CJL, Lopez AD. Geneva: World Health Organization; 1994:3-19.

33. Murray CJL: Rethinking DALYs. In The global burden of disease: a comprehensive assessment of mortality and disability from diseases, injuries and risk factors in 1990 and projected to 2020 Edited by: Murray CJL, Lopez AD. Boston: Harvard University Press; 1996: I-98.

34. Murray CJL, Acharya AK: Understanding DALYs. I Health Econ 1997, 16:703-730.

35. Murray CJL, Lopez AD, Eds: The global burden of disease: a comprehensive assessment of mortality and disability from diseases, injuries and risk factors in 1990 and projected to 2020 Boston: Harvard University Press; 1996.

36. Coale A, Guo G: Revised regional model life tables at very low levels of mortality. Population Index 1989, 55:613-643. 
37. Fox-Rushby JA, Hanson K: Calculating and presenting disability adjusted life years (DALYs) in cost-effectiveness analysis. Health Policy Plan 200I, 16:326-331.

38. Vlassoff $C$, Tanner M: The relevance of rapid assessments to health research and interventions. Health Policy Plan 1992, 7:1-9.

39. Mabey D, Fraser-Hunt N: Antibiotics for trachoma Issue 2 The Cochrane Library. Oxford: Update Software; 2003.

40. Guyatt HL, Kinnear J, Burini M, Snow RW: A comparative cost analysis of insecticide-treated nets and indoor residual spraying in Highland Kenya. Health Policy Plan 2002, I7:144-I53.

41. Varley RCG: Child survival and environmental health interventions: a costeffectiveness analysis. Applied Study no. 4 Washington DC: Environmental Health Project; 1996.

42. Murphy H, Stanton B, Galbraith J: Prevention: environmental health interventions to sustain child health survival. Applied Study no. 3 Washington DC: Environmental Health Project; 1997.

43. Martines J, Phillips M, Feachem RGA: Diarrhoeal diseases. In Disease control priorities in developing countries Edited by: Jamison DT, Mosley WH, Measham AR, Bobadilla JL. New York: Oxford University Press; 1993:91-II6.

44. Pinstrup-Andersen P, Burger S, Habicht JP, Peterson K: Proteinenergy malnutrition. In Disease control priorities in developing countries Edited by: Jamison DT, Mosley WH, Measham AR, Bobadilla JL. New York: Oxford University Press; 1993:391-420.

45. Foster SO, McFarland DA, John AM: Measles. In Disease control priorities in developing countries Edited by: Jamison DT, Mosley WH, Measham AR, Bobadilla JL. New York: Oxford University Press; 1993:16I-187.

46. Jamison DT, Torres AM, Chen LC, Melnick JL: Poliomyelitis. In Disease control priorities in developing countries Edited by: Jamison DT, Mosley WH, Measham AR, Bobadilla JL. New York: Oxford University Press; 1993:117-129.

47. Gilson L, Mkanje R, Grosskurth H, Mosha F, Picard J, Gavyole A, Todd J. Mayaud P, Swai R, Fransen L, Mabey D, Mills A, Hayes R: Costeffectiveness of improved treatment services for sexually transmitted diseases in preventing HIV-I infection in Mwanza region, Tanzania. Lancet |997, 350:|805-|809.

48. Mayaud P, Mosha F, Todd J, Balira R, Mgara J, West B, Rusizoka M, Mwijarubi E, Gabone R, Gavyole A, Grosskurth H, Hayes R, Mabey D: Improved treatment services significantly reduce the prevalence of sexually transmitted diseases in rural Tanzania: results of a randomized controlled trial. AIDS 1997, I I:1873-1880.

49. Johannesson $M$, Weinstein MC: On the decision rules of costeffectiveness analysis. J Health Econ 1993, I 2:459-467.

50. Weinstein MC, Zeckhauser R: Critical ratios and efficient allocation. J Public Econ 1973, 2:147-157.

5I. Birch S, Gafni A: Cost effectiveness/utility analyses: do current decision rules lead us where we want to be? J Health Econ 1992, I I:279-296.

52. Cairns J: Discounting in economic evaluation. In Economic evaluation in health care Edited by: Drummond M, McGuire A. Oxford: Oxford University Press; 2001:236-255.

53. Robberstad B: Estimation of private and social time preferences for health in northern Tanzania. Soc Sci Med 2005, 6I:1597-1607.

54. Barnum H, Kutzin J: Public hospitals in developing countries: resource use, cost, financing Baltimore: The Johns Hopkins University Press; 1993.

55. Hansen K, Ghapman G, Chitsike I, Kasilo O, Mwaluko G: The costs of HIVIAIDS care at government hospitals in Zimbabwe. Health Policy Plan 2000, 15:432-440.

56. Brenzel L, Wolfson LJ, Fox-Rushby J, Miller M, Halsey NA: Vaccinepreventable diseases. In Disease control priorities in developing countries 2nd edition. Edited by: Jamison DT, Breman JG, Measham AR, Alleyne G, Claeson M, Evans DB, Jha P, Mills A, Musgrove P. New York: Oxford University Press; 2006:389-4II.

57. Elbasha HE, Messonnier ML: Cost-effectiveness analysis and health care resource allocation: decision rules under variable returns to scale. Health Econ 2004, I3:2I-35.

58. Murray CJL, Evans DB, Acharya A, Baltussen RMPM: Development of WHO guidelines on generalized cost-effectiveness analysis. Health Econ 2000, 9:235-25I.

59. Murray CJL, Kreuser J, Whang W: Cost-effectiveness analysis and policy choices: investing in health systems. In Global comparative assessments in the health sector: disease burden, expenditures and intervention packages Edited by: Murray CJL, Lopez AD. Geneva: World Health Organization; 1994:181-192.

60. Stinnett AA, Paltiel DA: Mathematical programming for the efficient allocation of health care resources. J Health Econ 1996, I5:64|-653.

6I. Haws RA, Thomas AL, Bhutta ZA, Darmstadt GL: Impact of packaged interventions on neonatal health: a review of the evidence. Health Policy Plan 2007, 22:193-215.

62. Task Force on Health Systems Research: Informed choices for attaining the Millennium Development Goals: towards an international cooperative agenda for health-systems research. The Lancet 2004, 364:997-1003.

63. Vundule C, Mharakurwa S: Knowledge, practices, and perceptions about malaria in rural communities of Zimbabwe - relevance for malaria control. Bull World Health Organ 1996, 74:55-60.

64. Wright J, Walley J, Philip A, Pushpananthan S, Dlamini E, Newell J, Dlamini S: Direct observation of treatment for tuberculosis: a randomized controlled trial of community health workers versus family members. Trop Med Int Health 2004, 9:559-565.

65. Pearson CR, Micek MA, Simoni JM, Hoff PD, Matediana E, Martin DP, Gloyd SS: Randomized controlled trial of peer-delivered, modified directly observed therapy for HAART in Mozambique. J Acquir Immune Defic Syndr 2007, 46:238-244.

66. Hongoro C, Lorenzoni L: Cost analysis for rehabilitation services in Zimbabwe Harare: Government of Zimbabwe, Blair Research Institute, Ministry of Health and Child Welfare; 1994.

67. Hongoro C: Purchaser/provider relationships in health care: the government and mission health care providers in Zimbabwe Harare: Government of Zimbabwe, Blair Research Institute, Ministry of Health and Child Welfare; 1995.

68. Bijlmakers L, Chihanga S: District health service costs, resource adequacy and efficiency: a comparison of three districts Harare: Government of Zimbabwe, Ministry of Health and Child Welfare and UNICEF Zimbabwe; 1995 .

69. Canning D: The economics of HIVIAIDS in low-income countries: the case for prevention. J Econ Perspectives 2006, 20: $121-142$

70. Kapiriri L, Martin DK: Bedside rationing by health practitioners: a case study in a Ugandan hospital. Med Decis Making 2007, 27:44-52.

7I. Baltussen R, Stolk E, Chisholm D, Aikins M: Towards a multi-criteria approach for priority setting: an application to Ghana. Health Econ 2006, I 5:689-696.

72. Makundi E, Kapiriri L, Norheim OF: Combining evidence and values in priority setting: testing the balance sheet method in a low-income country. BMC Health Serv Res 2007, 7:152.

73. Kapiriri L, Martin DK: A strategy to improve priority setting in developing countries. Health Care Anal 2007, 15:159-167.

Publish with Bio Med Central and every scientist can read your work free of charge

"BioMed Central will be the most significant development for disseminating the results of biomedical research in our lifetime. "

Sir Paul Nurse, Cancer Research UK

Your research papers will be:

- available free of charge to the entire biomedical community

- peer reviewed and published immediately upon acceptance

- cited in PubMed and archived on PubMed Central

- yours - you keep the copyright
BioMedcentral 